\title{
Effects of peripherally administered urocortin 3 on feeding behavior and gastric emptying in mice
}

\author{
MUTSUMI TERASHI, AKIHIRO ASAKAWA, KAI-CHUN CHENG, KEN-ICHIRO KOYAMA, \\ HUKE CHAOLU, MIHARU USHIKAI and AKIO INUI
}

Department of Psychosomatic Internal Medicine, Kagoshima University

Graduate School of Medical and Dental Sciences, Kagoshima 890-0852, Japan

Received September 16, 2010; Accepted January 4, 2011

DOI: $10.3892 /$ etm.2011.200

\begin{abstract}
Human and mouse urocortin 3 (Ucn3) were first identified in 2001. Ucn3 binds selectively to corticotropinreleasing factor receptor type 2 (CRF-R2). Previous studies have shown that centrally administered Ucn3 decreases food intake in rats. However, the role of Ucn3 in the regulation of gut motility remains to be determined. In the present study, we investigated the effects of peripherally administered Ucn3 on food intake and gastric emptying in mice. After intraperitoneal (i.p.) administration of Ucn3, food intake was measured in the light and dark phases, and the rate of gastric emptying was determined. We found that i.p. administration of Ucn3 significantly inhibited feeding behavior in mice, and significantly delayed gastric emptying 1-2 $\mathrm{h}$ after administration in a dose-dependent manner. These results suggest that Ucn3 contributes to the modulation of feeding behavior and gut motility. Thus, Ucn3 and CRF-R2 may be involved in the pathogenesis of functional gastrointestinal and eating disorders.
\end{abstract}

\section{Introduction}

Corticotropin-releasing factor (CRF), a 41-amino acid peptide, was first isolated from the ovine hypothalamus in $1981(1,2)$. CRF, acting through the hypothalamic-pituitary-adrenal axis, is a major mediator of the response to stress, and plays a key role in the regulation of anxiety-like behavior and energy

Correspondence to: Dr Akihiro Asakawa, Department of Psychosomatic Internal Medicine, Kagoshima University Graduate School of Medical and Dental Sciences, 8-35-1 Sakuragaoka, Kagoshima 890-8520, Japan

E-mail: asakawa@m2.kufm.kagoshima-u.ac.jp

Abbreviations: CRF, corticotropin-releasing factor; CRF-R1, CRF receptor type 1; CRF-R2, CRF receptor type 2; i.p., intraperitoneal(-ly); SE, standard error; Ucn1, urocortin 1; Ucn2, urocortin 2; Ucn 3 , urocortin 3

Key words: urocortin 3, feeding, gastric emptying, corticotropinreleasing factor balance (3). The CRF system consists of two CRF receptor subtypes: CRF receptor type 1 (CRF-R1) and CRF receptor type 2 (CRF-R2) (3-5). CRF-R1 is implicated in anxiety behavior $(3,6-8)$, while CRF-R2 is involved in feeding behavior and gut motility $(3,9,10)$.

Rat urocortin 1 (Ucn1), a 40-amino acid peptide, was identified in the rat brain in 1995 (11). Ucn1 is structurally similar to $\mathrm{CRF}$ and binds to CRF-R1 and CRF-R2. Mouse urocortin 2 (Ucn2), a 38-amino acid peptide, was identified in the mouse brain in 2001 (12) and exhibits a more potent affinity for CRF-R2 than for CRF-R1. Human and mouse urocortin 3 (Ucn3) are 38-amino acid peptides that were also identified in $2001(13,14)$. Ucn3 binds selectively to CRF-R2. Mouse Ucn3 mRNA expression has been detected in the hypothalamus, amygdalae, brainstem, small intestine and skin of mice (14). Previous studies have shown that centrally administered Ucn3 decreases food intake in rats (15). Recently, Czimmer et al showed that intracisternal administration of Ucn2 into conscious rats inhibited gastric emptying of a viscous noncaloric meal (16). However, the role of Ucn3 in the regulation of gut motility remains to be determined.

In this study, we investigated the effects of peripherally administered Ucn3 on food intake and gastric emptying in mice.

\section{Materials and methods}

Animals and chemicals. Seven-week-old C57BL/6L male mice weighing 19-24 g (Clea Japan, Inc., Tokyo, Japan) were used in this study. The mice were individually housed in a regulated environment $\left(23 \pm 1^{\circ} \mathrm{C}, 55 \pm 10 \%\right.$ humidity, $12: 12 \mathrm{~h}$ light:dark cycle, with lights on at 07:00 am). Food and water were available ad libitum, except when otherwise indicated.

Experiments were approved by the Laboratory Animal Committees of Kagoshima University Graduate School and were performed according to the Guidelines for the Care and Use of Laboratory Animals, which are standardized to the Japanese national guidelines.

Mouse Ucn3 (FW 4171.56; purity $\geq 95 \%$ ) was purchased from Phoenix Pharmaceuticals, Inc. (CA, USA). Prior to the experiments, the mouse Ucn3 was diluted in $100 \mu \mathrm{l}$ of physiological saline (Otsuka, Tokyo, Japan). An equal amount of physiological saline served as the control solution. 


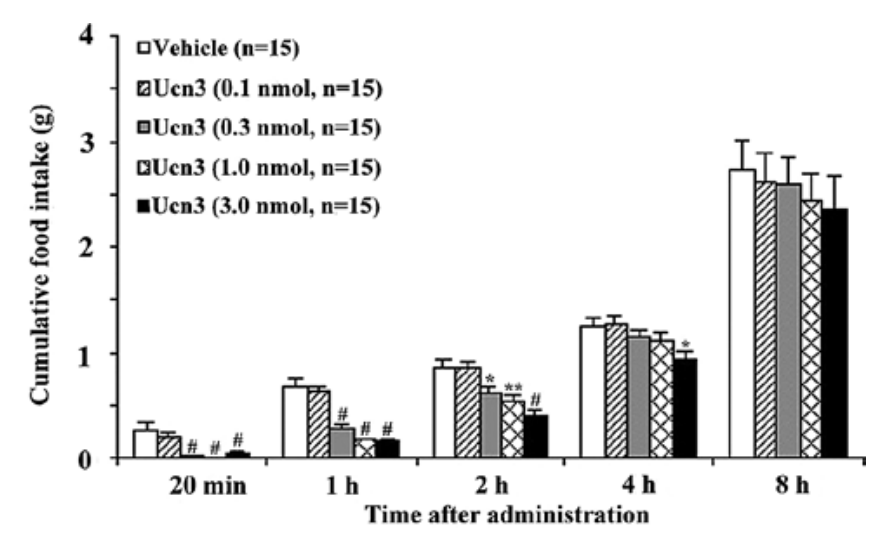

Figure 1. Inhibitory effect of i.p. administration of Ucn3 (0.1-3 nmol/mouse) on cumulative food intake in food-deprived mice in the light-phase feeding experiments. Error bars, mean $\pm \mathrm{SE}$; $\mathrm{n}$, number of mice used. ${ }^{*} \mathrm{P}<0.05,{ }^{* *} \mathrm{P}<0.01$ and ${ }^{*} \mathrm{P}<0.001$, statistically significant difference compared to the controls.

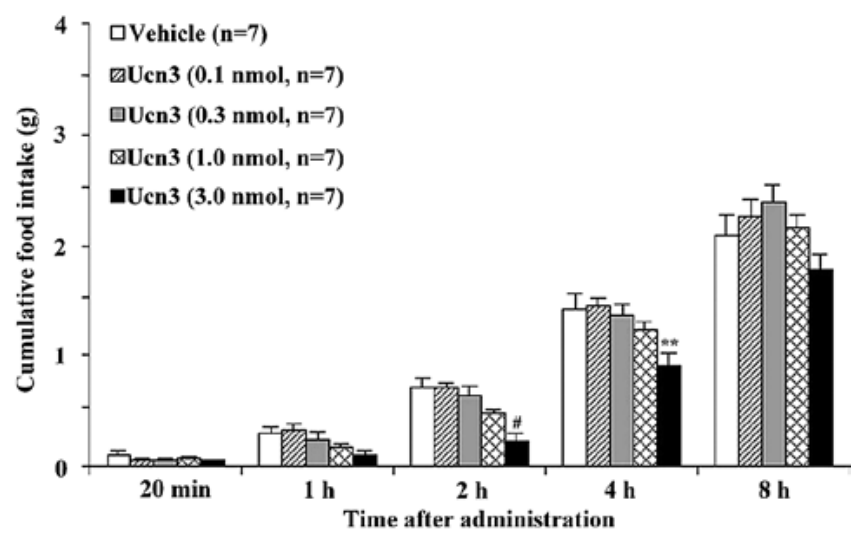

Figure 2. Inhibitory effect of i.p. administration of Ucn3 (0.1-3 nmol/mouse) on cumulative food intake in non-food-deprived mice in the dark-phase feeding experiments. Error bars, mean $\pm \mathrm{SE}$; $\mathrm{n}$, number of mice used. ${ }^{* *} \mathrm{P}<0.01$ and ${ }^{\#} \mathrm{P}<0.001$, statistically significant difference compared to the controls.

Food intake experiments. Mice were provided with a standard diet (CE-2; Clea Japan, Inc.). Experiments were performed during the light and dark phases. Light-phase experiments were started at 08:30 am. Before the feeding tests were conducted, the mice were deprived of food for $16 \mathrm{~h}$, but were allowed free access to water. After i.p. administration of Ucn3, the mice were allowed free access to a pre-weighed quantity of food. Food intake was calculated by subtracting the uneaten food from the initial quantity of food at $20 \mathrm{~min}, 1,2,4$ and $8 \mathrm{~h}$, taking into account food spillage. Dark-phase food intake experiments were started at 07:00 pm, and the mice were allowed free access to food and water before the experiments. After i.p. administration of Ucn3, food intake was calculated by subtracting the uneaten food from the initial quantity of food at $20 \mathrm{~min}, 1,2,4$ and $8 \mathrm{~h}$, taking into account food spillage. Cumulative food intake was calculated at $20 \mathrm{~min}, 1,2,4$ and $8 \mathrm{~h}$.

Gastric emptying experiment. Prior to the gastric emptying experiments, the mice were deprived of food for $16 \mathrm{~h}$, but were allowed free access to water. The fasted mice were given free access to a pre-weighed quantity of food for $1 \mathrm{~h}$. The mice were deprived of food again for 1 or $2 \mathrm{~h}$ after i.p. administration. Food intake was calculated by weighing the

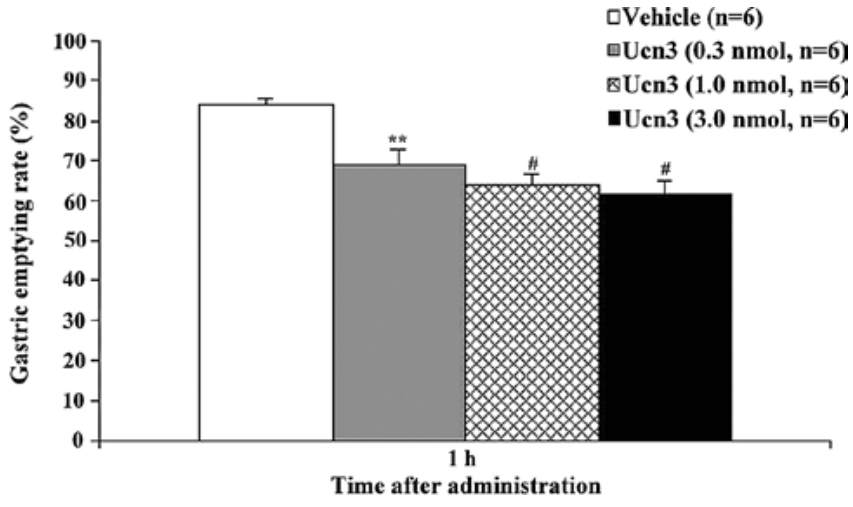

Figure 3. Inhibitory effect of i.p. administration of Ucn3 (0.1-3 nmol/mouse) on the gastric emptying rate $1 \mathrm{~h}$ after Ucn 3 administration. Error bars, mean $\pm \mathrm{SE}$; $\mathrm{n}$, number of mice used. ${ }^{* *} \mathrm{P}<0.01$ and ${ }^{\#} \mathrm{P}<0.001$, statistically significant difference compared to the controls.

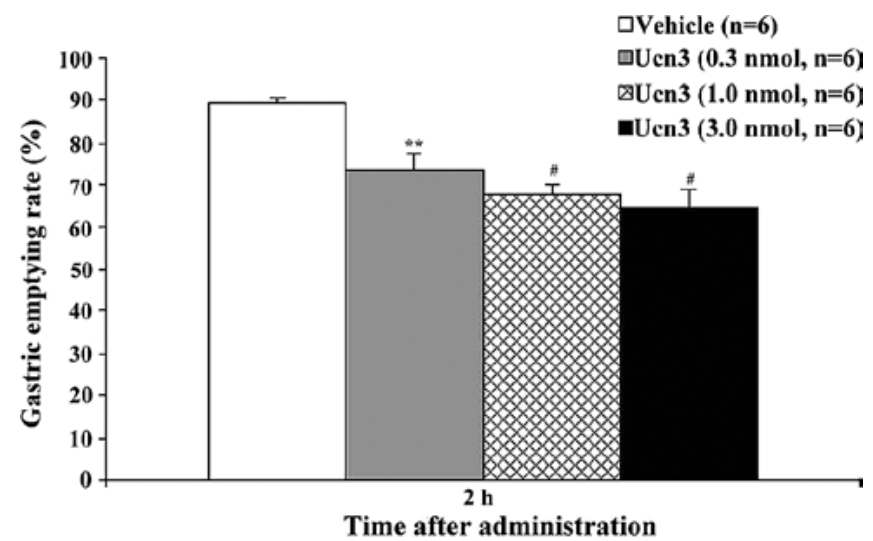

Figure 4. Inhibitory effect of i.p. administration of Ucn3 (0.1-3 nmol/mouse) on the gastric emptying rate $2 \mathrm{~h}$ after Ucn3 administration. Error bars, mean $\pm \mathrm{SE}$; $\mathrm{n}$, number of mice used. ${ }^{* *} \mathrm{P}<0.01$ and ${ }^{\#} \mathrm{P}<0.001$, statistically significant difference compared to the controls.

amount of uneaten food as described above. The mice were sacrificed by cervical dislocation 2 or $3 \mathrm{~h}$ after the start of the experiments. Immediately after the mice were sacrificed, laparotomy was performed to expose the stomach, which was then quickly ligated at the pylorus and cardia, and removed. The contents were dried using a vacuum freeze-drying system (Model 7670500; Labconco Corp., MO, USA), and the dry content was weighed. Gastric emptying was calculated using the formula: Gastric emptying $(\%)=[1-($ dry weight of recovered food from the stomach/weight of food intake)] x 100.

Statistical analysis. The effects of different doses of Ucn3 were evaluated by an a priori Dunnett's test. Results from mice administered the specified individual doses of Ucn3 were compared to results from mice that received the saline control solution. For all comparisons, P-values $<0.05$ were considered to be statistically significant. Results are expressed as the mean \pm standard error (SE).

\section{Results}

To investigate whether Ucn 3 influences feeding behavior, we first examined the effects of an i.p. administration of Ucn3 
(0.1-3 nmol/mouse) on food intake in food-deprived mice during the light-phase. In these mice, it was found that Ucn3 significantly inhibited feeding behavior in a dose-dependent manner (Fig. 1). Cumulative food intake significantly decreased from $20 \mathrm{~min}$ to $2 \mathrm{~h}$ after $\mathrm{Ucn} 3$ administration. We then investigated the effects of Ucn 3 (0.1-3 nmol/mouse) on food intake in non-food-deprived mice during the darkphase. It was found that Ucn3 significantly decreased food intake 2-4 $\mathrm{h}$ after its administration (Fig. 2). Lastly, we examined whether Ucn3 influences the gastric emptying rate. It was found that Ucn3 significantly delayed gastric emptying 1-2 $\mathrm{h}$ after its administration in a dose-dependent manner (Figs. 3 and 4).

\section{Discussion}

To date, various hormones including leptin and ghrelin have been reported to be involved in feeding behavior. We previously reported that peripherally administered Ucn1 was more potent than $\mathrm{CRF}$ in the regulation of anorexigenic activity when the two were administered at the same doses (17). Ohata and Shibasaki found that intracerebroventricular administration of Ucn 3 and Ucn 2 decreased food intake in rats fed ad libitum (15). In our study, peripherally administered Ucn3 reduced food intake as effectively as the other CRF family peptides, and mediated anorexigenic activity in both the light- and dark-phase experiments.

It has been shown that gastrointestinal motility influences feeding behavior. Considerable evidence indicates that delayed gastric emptying is closely related to anorexia and cachexia, while rapid gastric emptying is found to be associated with overeating and obesity $(18,19)$. We previously reported that Ucn1 more potently suppressed gastric emptying than did CRF when the two were administered at the same doses (17). Gourcerol et al reported that peripheral administration of Ucn2 delays gastric emptying in mice (20). In our study, peripherally administered Ucn3 inhibited gastric emptying as effectively as other CRF family peptides. Recently, Liu et al reported that Ucn1, 2 and 3 function as neuromodulators and influence the excitatory action of myenteric neurons (21). The induction of the excitatory action of myenteric neurons by Ucn1 was primarily mediated by CRF-R1, whereas its induction by Uen 2 and Uen3 was mediated by CRF-R2 (21). Previous studies have shown that CRF-R2 is present in various peripheral tissues, including the gastrointestinal tract (22).

These findings and the results of the present study indicate that Ucn3 and other CRF family peptides are involved in the development of functional gastrointestinal and eating disorders. Ucn3 and CRF-R2 may therefore be promising targets for the treatment of various diseases.

\section{Acknowledgements}

The authors wish to thank all the staff members of the Institute of Laboratory Animal Sciences, Kagoshima University (Frontier Science Research Center) who maintained the animals under satisfactory conditions. We also wish to thank the Joint Research Laboratory, Kagoshima University Graduate School of Medical and Dental Science, for the use of their facilities.

\section{References}

1. Vale W, Spiess J, Rivier C and Rivier J: Characterization of a 41-residue ovine hypothalamic peptide that stimulates secretion of corticotropin and beta-endorphin. Science 213: 1394-1397, 1981.

2. Spiess J, Rivier J, Rivier C and Vale W: Primary structure of corticotropin-releasing factor from ovine hypothalamus. Proc Natl Acad Sci USA 78: 6517-6521, 1981.

3. Denver RJ: Structural and functional evolution of vertebrate neuroendocrine stress systems. Ann NY Acad Sci 1163: 1-16, 2009.

4. Perrin MH, Donaldson CJ, Chen R, Lewis KA and Vale WW: Cloning and functional expression of a rat brain corticotropin releasing factor (CRF) receptor. Endocrinology 133: 3058-3061, 1993.

5. Chen R, Lewis KA, Perrin MH and Vale WW: Expression cloning of a human corticotropin-releasing-factor receptor. Proc Natl Acad Sci USA 90: 8967-8971, 1993.

6. Vita N, Laurent P, Lefort S, et al: Primary structure and functional expression of mouse pituitary and human brain cortico-trophin releasing factor receptors. FEBS Lett 335: 1-5, 1993.

7. Chang CP, Pearse RV II, O'Connell S and Rosenfeld MG: Identification of a seven transmembrane helix receptor for corticotropin-releasing factor and sauvagine in mammalian brain. Neuron 11: 1187-1195, 1993.

8. Potter E, Sutton S, Donaldson C, et al: Distribution of corticotropin-releasing factor receptor mRNA expression in the rat brain and pituitary. Proc Natl Acad Sci USA 91: 8777-8781, 1994.

9. Lovenberg TW, Liaw CW, Grigoriadis DE, et al: Cloning and characterization of a functionally distinct corticotropin-releasing factor receptor subtype from rat brain. Proc Natl Acad Sci USA 92: 836-840, 1995.

10. Chalmers DT, Lovenberg TW and De Souza EB: Localization of novel corticotropin-releasing factor receptor (CRF2) mRNA expression to specific subcortical nuclei in rat brain: comparison with CRF1 receptor mRNA expression. J Neurosci 15: 6340-6350, 1995.

11. Vaughan J, Donaldson C, Bittencourt J, et al: Urocortin, a mammalian neuropeptide related to fish urotensin I and to corticotropin-releasing factor. Nature 378: 287-292, 1995.

12. Reyes TM, Lewis K, Perrin MH, et al: Urocortin II: a member of the corticotropin-releasing factor (CRF) neuropeptide family that is selectively bound by type 2 CRF receptors. Proc Natl Acad Sci USA 98: 2843-2848, 2001.

13. Hsu SY and Hsueh AJ: Human stresscopin and stresscopin-related peptide are selective ligands for the type 2 corticotropin-releasing hormone receptor. Nat Med 7: 605-611, 2001.

14. Lewis K, Li C, Perrin MH, et al: Identification of urocortin III, an additional member of the corticotropin-releasing factor (CRF) family with high affinity for the CRF2 receptor. Proc Natl Acad Sci USA 98: 7570-7575, 2001.

15. Ohata $\mathrm{H}$ and Shibasaki T: Effects of urocortin 2 and 3 on motor activity and food intake in rats. Peptides 25: 1703-1709, 2004

16. Czimmer J, Million M and Taché Y: Urocortin 2 acts centrally to delay gastric emptying through sympathetic pathways while CRF and urocortin 1 inhibitory actions are vagal dependent in rats. Am J Physiol Gastrointest Liver Physiol 290: G511-G518, 2006.

17. Tanaka C, Asakawa A, Ushikai M, et al: Comparison of the anorexigenic activity of CRF family peptides. Biochem Biophys Res Commun 390: 887-891, 2009.

18. Duggan JP and Booth DA: Obesity, overeating, and rapid gastric emptying in rats with ventromedial hypothalamic lesions. Science 231: 609-611, 1986.

19. Phillips RJ and Powley TL: Gastric volume rather than nutrient content inhibits food intake. Am J Physiol 271: R766-R769, 1996.

20. Gourcerol G, Wang L, Wang YH, Million M and Taché Y: Urocortins and cholecystokinin-8 act synergistically to increase satiation in lean but not obese mice: involvement of corticotropin-releasing factor receptor-2 pathway. Endocrinology 148: 6115-6123, 2007.

21. Liu S, Ren W, Qu MH, et al: Differential actions of urocortins on neurons of the myenteric division of the enteric nervous system in guinea pig distal colon. Br J Pharmacol 159: 222-236, 2010.

22. Chatzaki E, Murphy BJ, Wang L, et al: Differential profile of $\mathrm{CRF}$ receptor distribution in the rat stomach and duodenum assessed by newly developed CRF receptor antibodies. J Neurochem 88: 1-11, 2004. 